\title{
Cervical Spine Trauma
}

\author{
Rully Hanafi Dahlan ${ }^{I}$, Sevline Estethia Ompusunggu', Ismail M. \\ Baselim $^{3}$, Yustinus Robby B. G. ${ }^{3}$ \\ ${ }^{1}$ Head of Neurospine, Peripheral Nerve, and Pain Division, Department of Neurosurgery, Medical \\ Faculty of Padjadjaran University, Hasan Sadikin Teaching Hospital \\ ${ }^{2}$ Staff of of Neurospine, Peripheral Nerve, and Pain Division, Department of Neurosurgery, Medical \\ Faculty of Padjadjaran University, Hasan Sadikin Teaching Hospital \\ ${ }^{3}$ Neurosurgery Resident, Department of Neurosurgery, Medical Faculty of Padjadjaran University, \\ Hasan Sadikin Teaching Hospital
}

\begin{abstract}
Cervical trauma is a serious condition, that may cause permanent disability or even death. Cervical trauma occurs in 2-7\% of blunt trauma patients. In Europe, the incidence of cervical trauma is approximately $9-17 / 100,000$ annually,. The most common mechanisms of injury causing cervival trauma are traffic accidents and falls, which the most commonly injured vertebra is vertebral C2 (axis). Diagnostics of cervical trauma are based on good clinical assessment and prompt radiological imaging. Several patient groups, such as the elderly and patients with traumatic brain injury are highly susceptible to cervical trauma. The diagnostics of cervivcal trauma remain challenging for clinical practitioners and failure to diagnose cervical trauma in acute care may have serious consequences.
\end{abstract}

Keywords : Cervical Trauma, High Incidence, Early and Prompt Management

\begin{abstract}
Abstrak. Trauma servikal adalah kondisi serius, yang dapat menyebabkan disabililitas permanen atau bahkan kematian. Trauma servikal terjadi pada 2-7\% pasien dengan trauma tumpul. Di Eropa, insidensi dari trauma servukal adalah 9-17/100,000 per tahun. Mekanisme tersering cedera yang menyebabkan trauma servikal adalah kecelakaan lalu lintas dan terjatuh, dengan vertebra terbanyak yang mengalami cedera adalah C2 (Axis). Diagnosis dari trauma servikal didasarkan atas penilaian klinis yang baik dan pencitraan radiologi. Beberapa kelompok pasien, seperti orang tua dan pasien dengan cedera kepala traumatic memiliki kemungkinan tinggi menderita trauma servikal. Diagnosis dari trauma servikal tetap menjadi tantangan bagi praktisi umum dan kegagalan dalam mendiagnosis trauma servikal pada rawatan akut dapat menyebabkan konsekuensi yang serius.
\end{abstract}

Kata Kunci : Trauma Servikal, Insidensi Tinggi, Tatalaksana Awal

Received [2 Nov 2019] | Revised [28 Nov 2019] | Accepted [1 Dec 2019]

\section{Introduction}

Management of cervical trauma continues to be a clinical challenge today. Injury to cervical spine can be a minor distension or major injury leading to tetraplegia or even death. ${ }^{1}$ Approximately $2-7 \%$ of blunt trauma patients suffer a cervical trauma. ${ }^{2}$ The estimated incidence

\footnotetext{
*Corresponding author at: Spine peripheral \& Pain division, Departement of Neurosurgery, Hasan Sadikin Hospital, Padjadjaran University
} 
of cervical trauma, in countries with similar population demographics to Finland (e.g., Norway, Sweden, Canada), is about 9-17/100,000. ${ }^{3}$

As cervical trauma can be prevented, it is important to understand its epidemiological features in order to prevent to high-risk groups. Cervical trauma occurs in all demographic categories, but incidence rates and other epidemiological features differ depending on geographical and cultural differences. ${ }^{4}$ The most typical trauma mechanisms in cervical trauma are traffic accidents and falls. It is estimated that $30 \%$ of people aged 65 or older fall every year. The incidence of fall-related cervical trauma among elderly patients has increased during the past decades. $^{5}$

Clinical examination is important to diagnose cervical trauma, however, clinical prediction rules are not operable in certain circumstances such as among patients with decreased level of consciousness, for example. Patients with $\mathrm{HI}$ and/or traumatic brain injury (TBI) comprise the largest group of patients where clinical examination alone is not sufficient to rule out cervical trauma. ${ }^{6}$

Assessment of spinal stability is important, as the choice of treatment in each specific type of cervical trauma is based on whether the injury is considered stable or not. The analysis of fractures is important in treatment planning. The axis (C2) is the most commonly injured cervical vertebra. Among headinjured patients, the patterns and distribution of cervical spine fractures is not well known.

\section{Literature Review}

\subsection{Anatomy and Biomechanics of the Cervical Spine}

The cervical spine consists of seven vertebrae $\mathrm{C} 1-\mathrm{C} 7$ and is a relatively complex anatomical structure. The atlas $(\mathrm{C} 1)$ and the axis $(\mathrm{C} 2)$ together with the occiput $(\mathrm{C} 0)$ comprise the upper cervical spine whereas vertebrae C3 to C7 comprise the subaxial or lower cervical spine. The atlas, the first cervical vertebra supports the head (hence its name) by two ellipsoid shaped facet joints which are seated in two bulky lateral masses. It is a solid bone ring and differs from all other vertebrae in lacking a body. The two lateral masses are connected at the front by an anterior arch and posteriorly by a longer posterior arch. Transverse processes of the atlas are unusually long making them adequate levers for the muscles which aid in the rotation of the head (Figure 2). The axis is the pivot on which the atlas rotates (Figure 3). It is distinguished by a strong special structure called the odontoid process (Dens), which rises perpendicularly from the body. 
The odontoid process has articulation in the anterior surface with the atlas, and in the posterior surface, the transverse ligament of the atlas grooves the odontoid process. The axis also has two facet joints with the atlas and two with the vertebra $\mathrm{C} 3$. The pedicles of the axis are stout and the laminae that provide attachment to ligamenta flava are thicker than in any other cervical vertebra. The spinous process is powerful and takes the pull of several muscles. The transverse processes of the axis are small. Approximately $50 \%$ of head rotation occurs at the atlanto-axial level and about $85 \%$ of the whole head and neck movements come from skull-atlas-axis complex. Vertebrae C3 to C7 all have somewhat similar appearance and consist of a body, pedicles, lateral masses/ articular processes, laminae, transverse processes and a spinous process (Figure 4). The size of the vertebrae in the lower cervical spine increases from top to bottom.

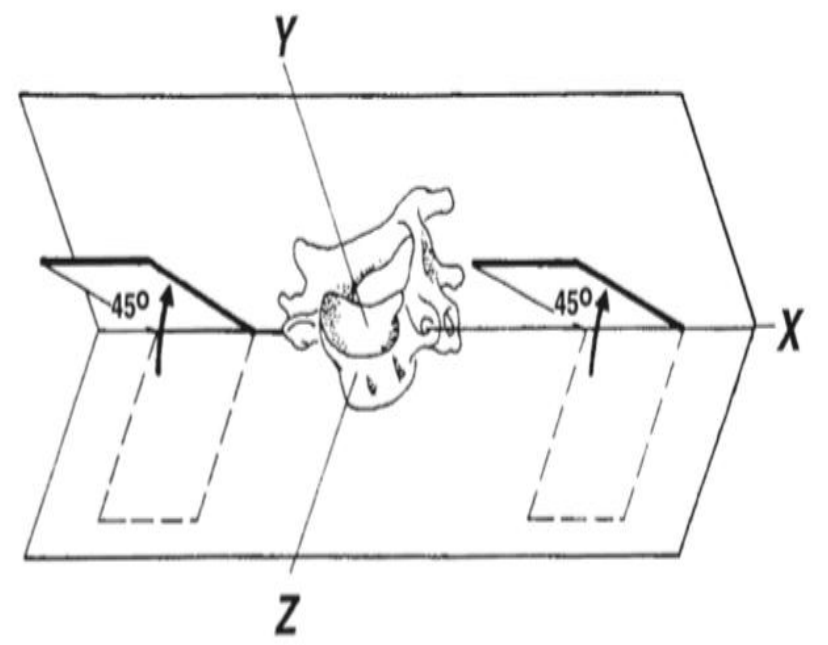

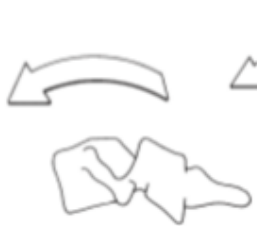

A

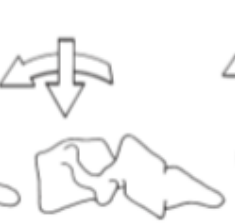

B

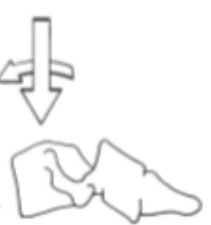

C

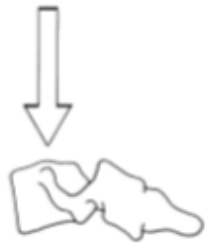

D

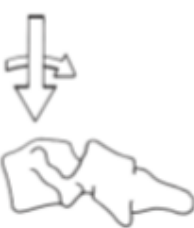

E

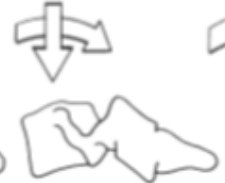

$\mathbf{F}$

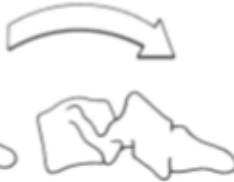

G

Figure 1. Biomechanics of Cervical Spine. The stability concept is ability of the spine, under physiologic loads, to maintain its pattern of displacement, so that there is no initial or additional neurologic deficit, no major deformity and no incapacitating pain

The most important stabilizing ligaments in the cervical spine are the anterior longitudinal ligament (ALL), the anterior atlanto-occipital membrane, the apical ligament, the paired alar ligaments, the cruciform ligament of the atlas, the posterior longitudinal ligament (PLL), the tectorial membrane (an upward extension of the PLL), the ligamentum flavum, the posterior atlanto-occipital membrane, the ligamentum nuchae, the interspinous ligaments, the intertransverse ligaments, and the articular capsules. Altogether, the cervical spine has 23 articulations: two $\mathrm{C} 0 / \mathrm{C} 1$ facet joints, two $\mathrm{C} 1 / \mathrm{C} 2$ facet joints and the odontoid process articulation with the $\mathrm{C} 1$ arch, and two facet joints plus an intervertebral disc in each of the six segments between $\mathrm{C} 2 / 3$ and $\mathrm{C} 7 / \mathrm{Th} 1$. The spinal cord is situated in the vertebral canal and continues as the medulla oblongata at the level of the odontoid process. The spinal nerve roots 
exit the spinal acanal via the intervertebral foramina except the first and second roots which exit the spinal canal posterior to the pedicles. The vertebral arteries arise from the subclavian arteries and supply blood to the posterior portion of the brain. They run upward through the foramina in the transverse processes of $\mathrm{C} 6$ (occasionally $\mathrm{C} 7$ ) to $\mathrm{C} 1$ to enter the skull through the foramen magnum. ${ }^{7}$
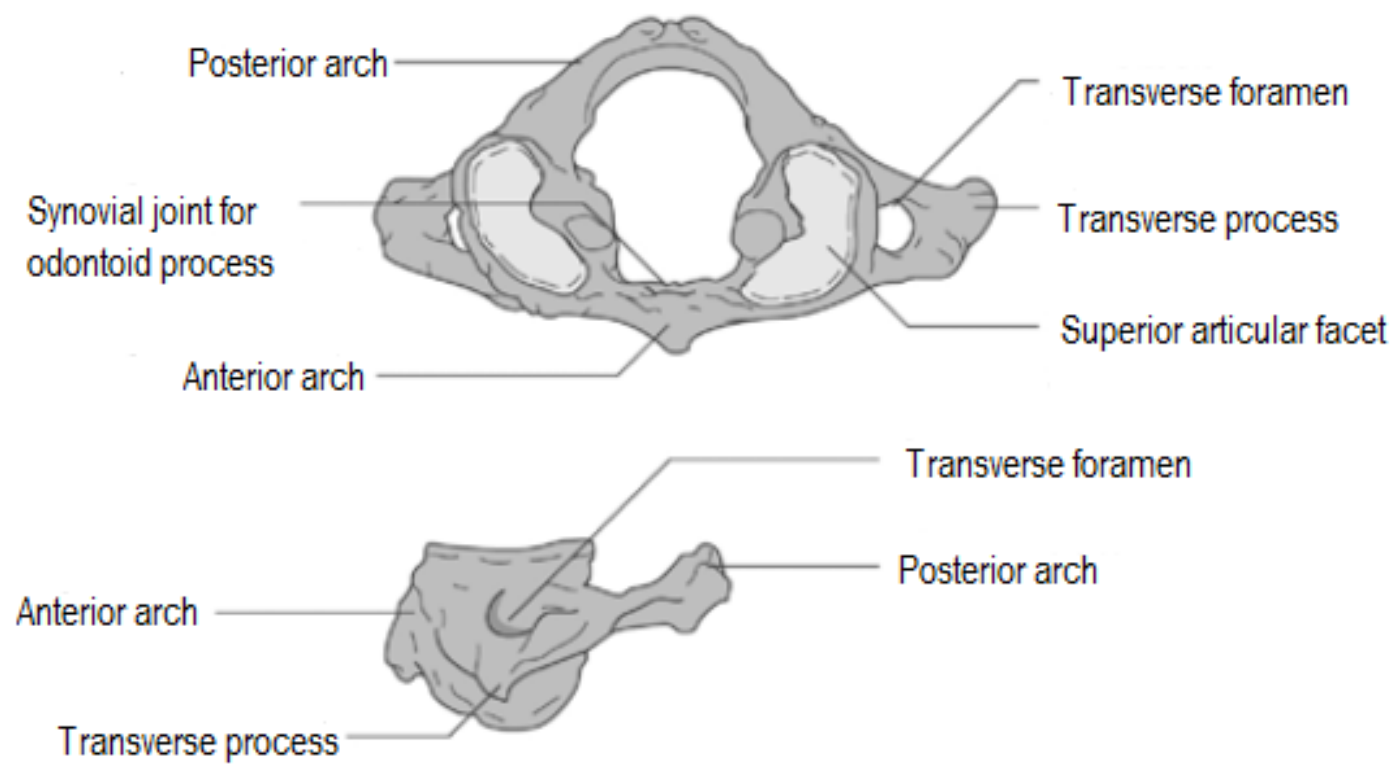

Figure 2. The atlas (C1) vertebra. Superior view (top) and lateral view (bottom). Modified from Gardner et al. (2005). ${ }^{8}$
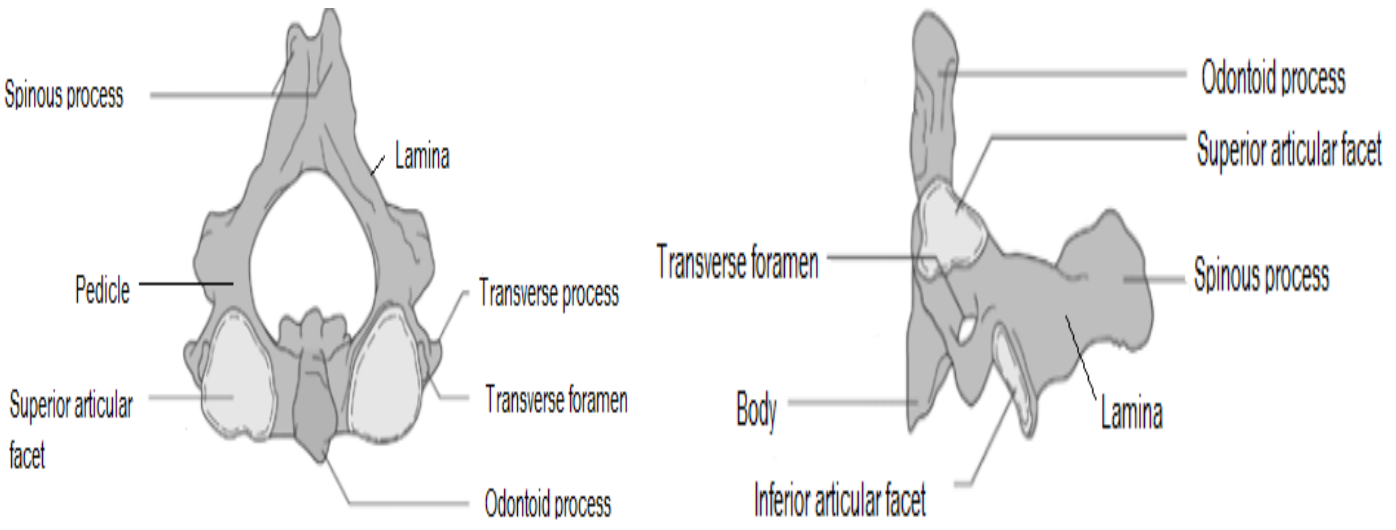

Figure 3. The axis (C2) vertebra. Superior view (top), and lateral view (bottom). Modified from Gardner et al. (2005). ${ }^{8}$ 


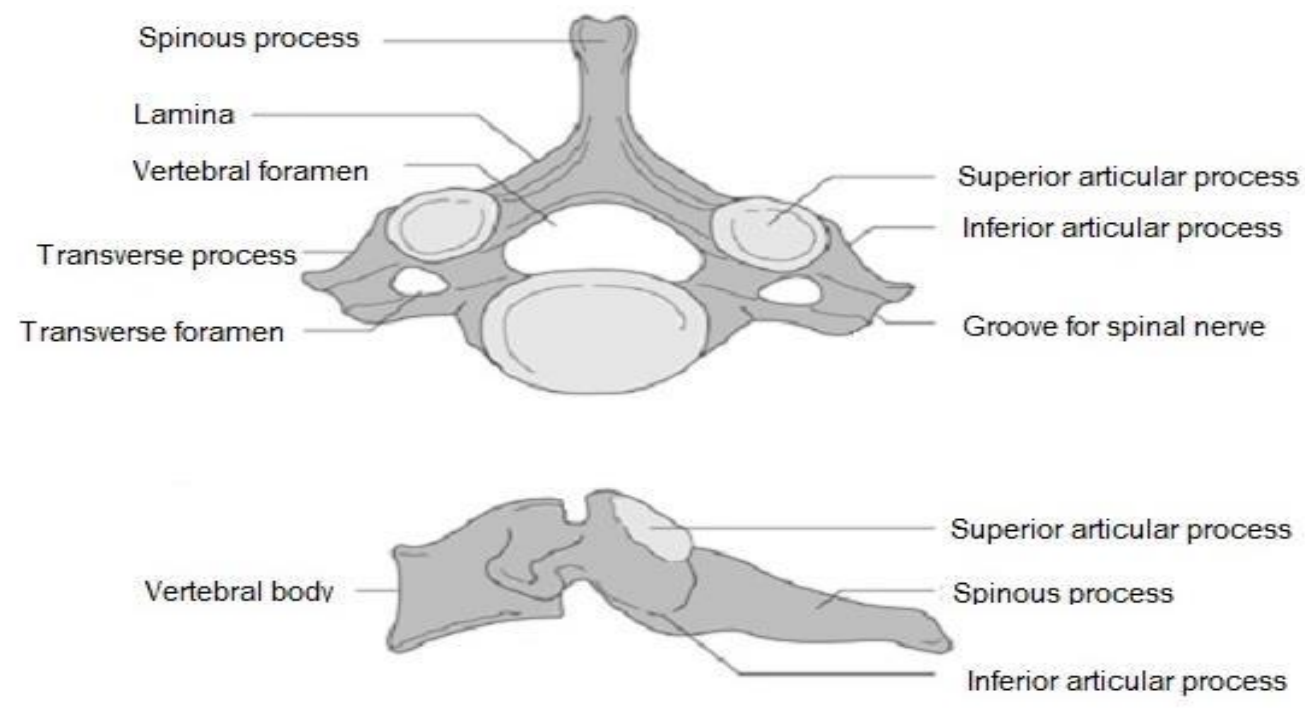

Figure 4. Typical subaxial vertebra. Superior view (top) and lateral view (bottom). Modified from Gardner et al. 2005. ${ }^{8}$

\subsection{Cervical Trauma Classification}

Accurate and efficient diagnosis and management of cervical trauma is necessary to avoid further neurological deficit. Assessment of spinal stability is essential as the choice of treatment in each specific type of cervical trauma is based on whether the injury is considered stable or not. Cervical trauma may be classified according to the level of injury $(\mathrm{C} 0-\mathrm{C} 7)$, mechanism of trauma, morphology, instability of the injury or neurological status. An ideal classification system would be simple, reproducible and highlight the injury characteristics that are relevant for the care of the patient. However, due to the wide spectrum of injuries to the cervical spine, it is difficult to create a comprehensive classification system. ${ }^{9}$
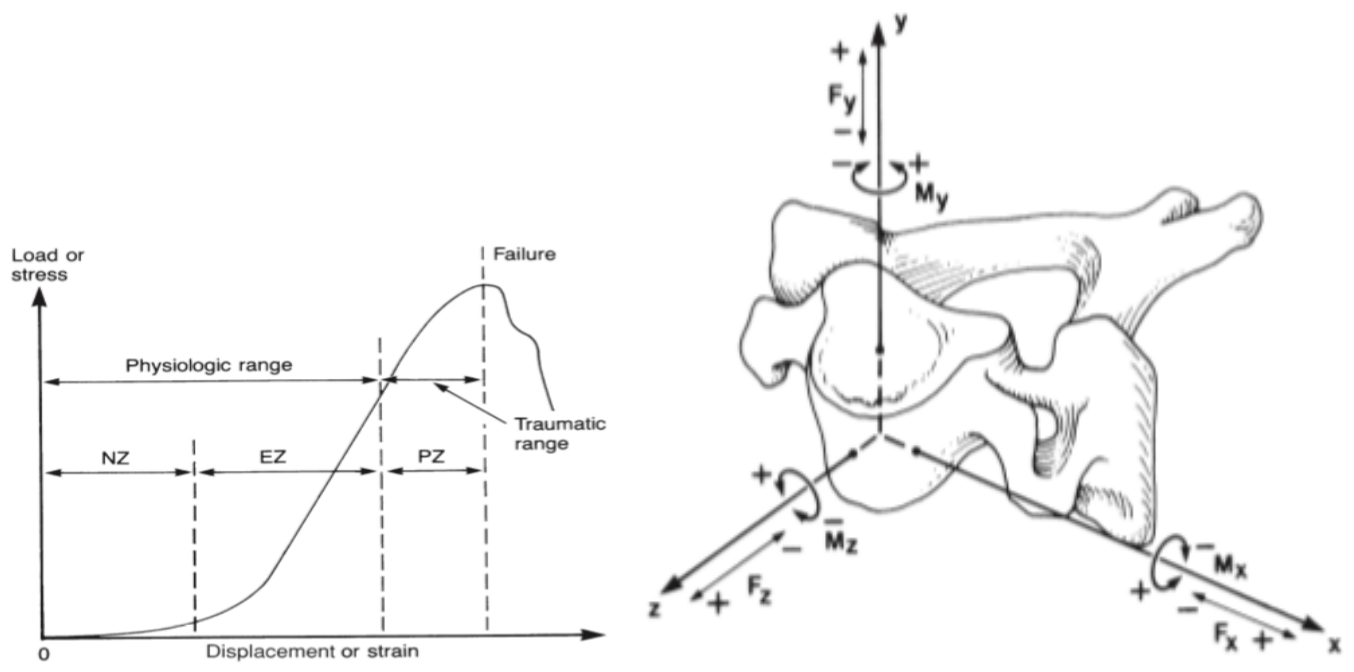

Figure 5. Kinematic of Cervical Spine 


\subsubsection{Craniovertebral junction (CVJ) injuries}

Craniovertebral junction (CVJ) refers to osseous structures consisting of the occipital bone surrounding the foramen magnum, the atlas and the axis. The key ligaments and membranes in the area are the alar ligaments, the cruciform ligament, the apical ligament, the atlantoaxial accessory ligament, the capsular joints, the tectorial membrane, and the anterior and posterior atlanto-occipital membrane. Ligaments and membranes in CVJ injuries have often been recognized but only recently (due to magnetic resonance imaging (MRI) and the increase in the knowledge of anatomical and biomechanical characteristics in the CVJ area) their role has been highlighted. ${ }^{10}$

Recent data emphasize the major role of the ligaments and membranes in CVJ injuries with a secondary function of osseous structures. Established classification systems in CVJ injuries are based on bony injuries even though CVJ stability is largely based on ligamentous integrity. A CVJ injury may occur with subtle physical examination findings and can have tragic consequences if missed. Many quantitative parameters are classically used to identify a CVJ distraction injury. However, it should be cautioned that craniometrics measurements may not exclude ligamentous instability. ${ }^{11}$

\subsubsection{Occipital condyle $(\mathrm{CO})$ fractures}

Occipital condyle fractures are relatively rare injuries. They are usually caused by high-energy trauma. They are difficult to identify in plain radiographs alone. However, due to the widespread use of CT in trauma evaluation, these injuries are encountered more frequently nowadays.

They occur in $0.4-0.7 \%$ of all major trauma patients who survive to the emergency department and represent less than $2 \%$ of all cervical spine fractures. In autopsy series, the incidence of $\mathrm{C} 0$ fractures has been reported to be as high as $4 \%$ in fatal head injuries. Anderson and Montesano (1988) were the first to classify occipital condyle fractures in three categories (Figure 6). Types I and II are considered clinically stable. In Type III there is a fracture-avulsion of the occipital condyle by the alar ligament and it is considered potentially unstable The classification scheme by Tuli et al. broadened the definition of stability to include also the atlantoaxial joint. In the presence of atlanto-occipital misalignment, surgical stabilization is recommended. ${ }^{12}$ 


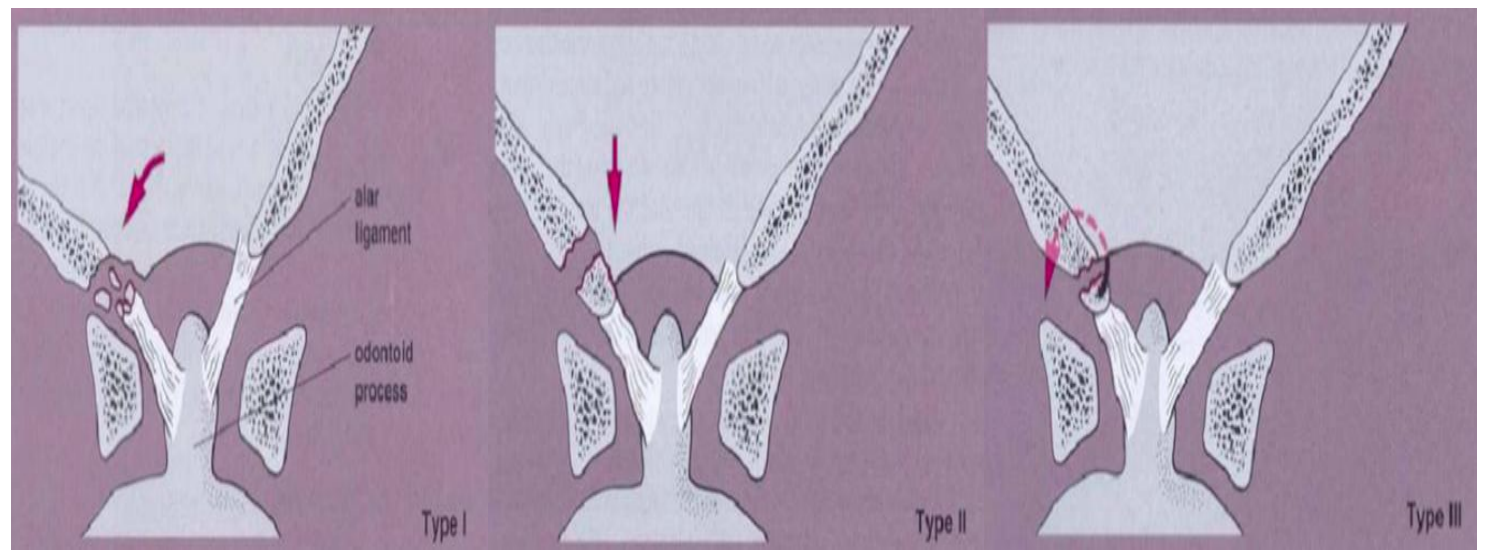

Figure 6. Anderson Mantesano Classification for Occipital Condyle Fracture. Type 1: Impaction. Type 2: Basilar Skull. Type 3: Occipital Condyle Avulsion

\subsubsection{Atlas (C1) fractures}

Atlas fractures account for about 9-11\% of all cervical fractures and they often occur in combination with axis (C2) fractures. Atlas fractures were first described by Jefferson in 1920. The management of atlas fractures is largely dependent on the integrity of the transverse atlantal ligament and whether the fracture occurs in isolation or in combination with other cervical spine fractures. The fracture may involve the anterior arch, the posterior arch, the lateral masses or a combination of these. The classic Jefferson fracture is a burst fracture with lateral displacement of the lateral masses (Figure 7). The most typical fracture type seen in clinical practice involves either the anterior or the posterior arch alone or a combination of these. ${ }^{13}$

There is no single classification system to accommodate all fracture types seen in clinical situations. The stability of atlas fractures has been based on the integrity of the transverse atlantal ligament. Based on the results by Spence et al. it has been suggested that if the sum of lateral displacement of the lateral masses is $7 \mathrm{~mm}$ or more, the transverse ligament is probably torn. According to the classification by Dickman et al., Type I involves intraligamentous disruption and Type II involves avulsion of the ligament's bony insertion. ${ }^{14}$ 


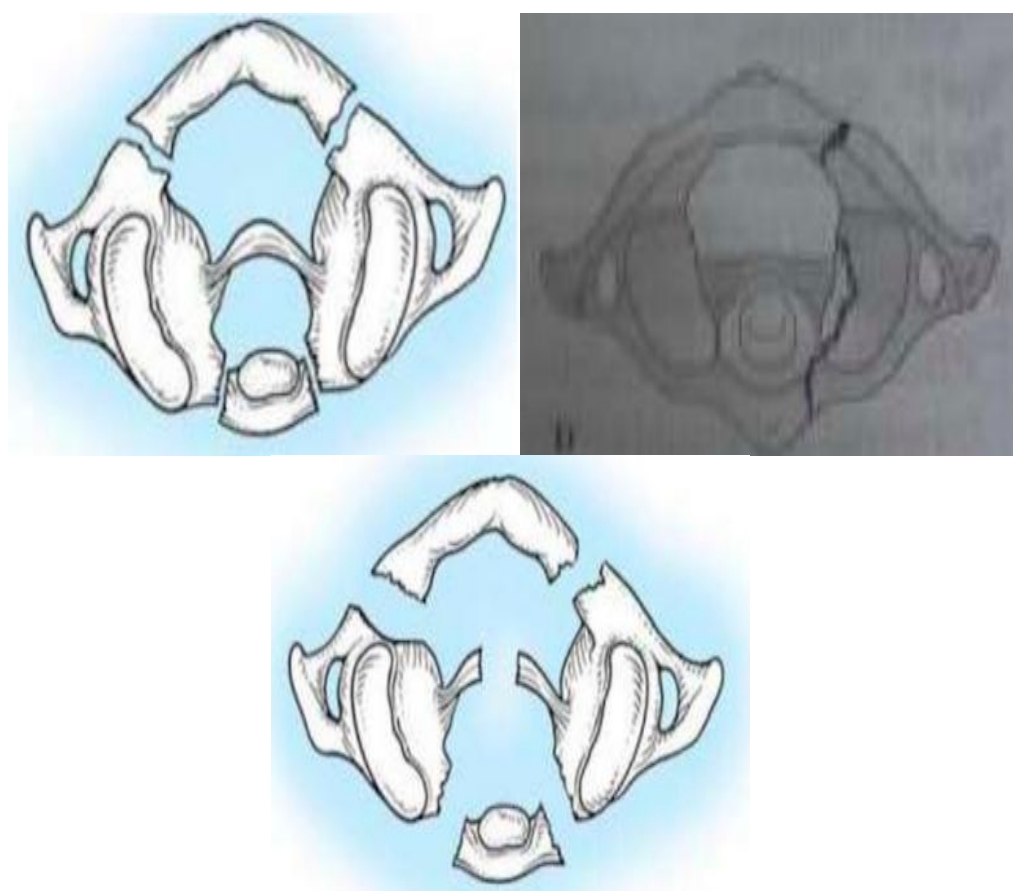

Figure 7. Landell's and Von Peter Classification of Atlas (C1) Fracture. Type I : Posterior Arch Fracture. Type II : Both Anterior-Posterior Arch (Jefferson Fracture). Type III : Lateral Atlantal Mass Fracture.

Atlanto-axial dislocation $(\mathrm{C} 1 / \mathrm{C} 2)$ may occur in three patterns and represents about $10 \%$ of cervical spine dislocations. In rotatory dislocation, one facet is dislocated anteriorly and the other posteriorly. Anterior dislocation is due to transverse ligament rupture or odontoid process fracture and posterior dislocation is due to anterior arch fracture of the atlas or odontoid process fracture. Rotatory dislocation is classified according to Fielding in four types based on severity (Figure 9). Type I injury may occur within physiological range of motion, Types II and III with ligament injuries and Type IV in conjunction with odontoid process insufficiency. ${ }^{15}$
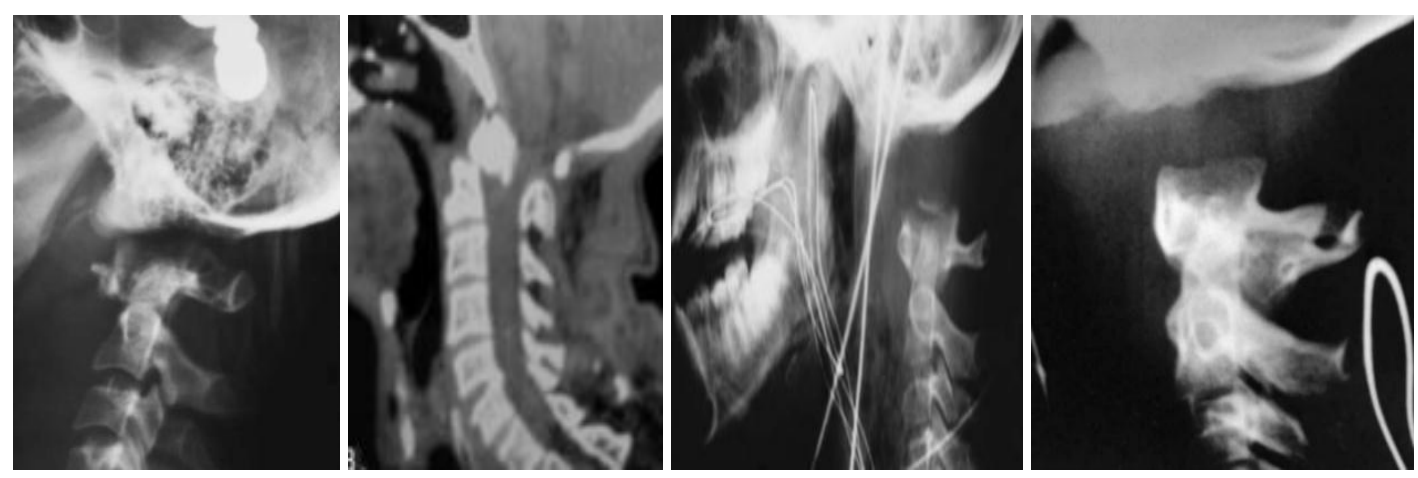

Figure 8. Traynalis and Coworkers Classification for Atlanto-Occipital Dislocation. Type 1 : Anterior Displacement of Occiput. Type 2 : Longitudinal Distraction/Vertical Displacement. Type 3 : Posterior Displacement. 


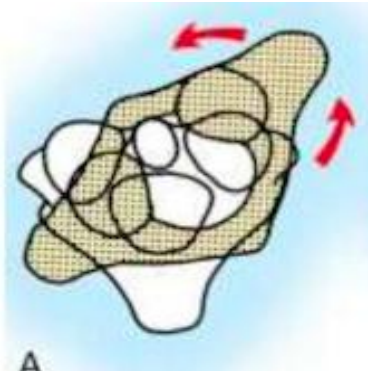

A

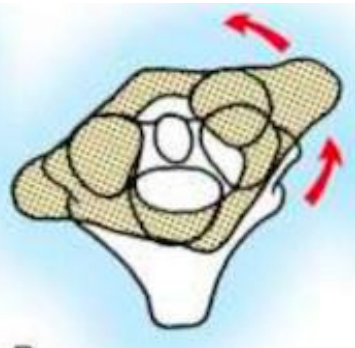

B

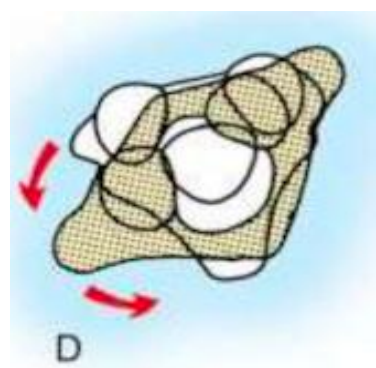

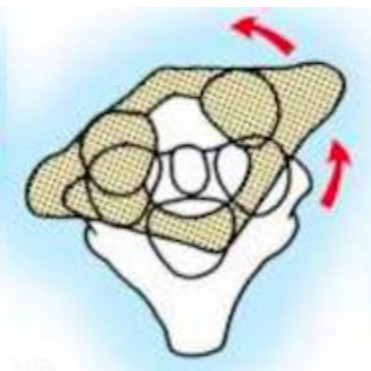

C

mm Anterior

Figure 9. Fielding and Hawkins Classification. Type $1:$ Simple. Type $2:$ with $3-5 \mathrm{~mm}$ Anterior
displacement. Type $3:$ with $>5 \mathrm{~mm}$ anterior displacement. Type $4:$ with Posterior displacement

\subsubsection{Axis (C2) fractures}

Fractures to the axis $(\mathrm{C} 2)$ are the most common cervical trauma. They account for approximately $20 \%$ of all cervical spine fractures and their incidence is especially high in older populations. Axis fractures can be divided into three distinct injury patterns: odontoid fractures, hangman's fractures and fractures of the body of the axis involving all other injuries to the $\mathrm{C} 2$ vertebra.

Odontoid fractures are the most common axis fractures. The classification of odontoid fractures was first developed by Anderson and D'Alonzo in 1974. Hadley et al. provided the widely accepted modification to the classification system which is based on the anatomical location of the fracture line. A Type I fracture, which is an alar ligament distractive avulsion of the odontoid tip, is considered stable and accounts for only 1-3\% of odontoid fractures. A Type II fracture occurs at the odontoid base and is considered unstable (Figure 11).

Approximately $50 \%$ to $60 \%$ of odontoid fractures are type II. Type IIA is a comminuted odontoid base fracture with additional chip fracture fragments at the odontoid base and is considered highly unstable. Only 5\% of Type II fractures belong to the IIA subclass. Type III fractures account for $36-42 \%$ of odontoid fractures and are characterized by a fracture line that extends downward into the cancellous portion of the body of the axis. Type III fractures are usually considered stable. In 2005, Grauer at al. proposed a modified and redefined classification system for Anderson and D’Alonzo Type I and III fractures in order to help in fracture management. ${ }^{16,17,18}$ 

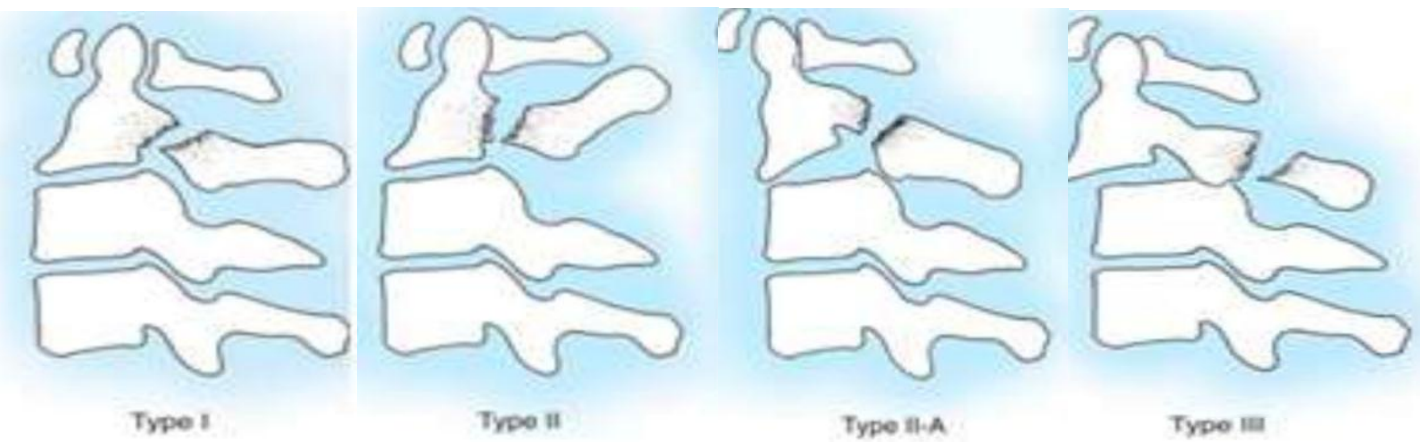

Figure 10. Levine and Edward Classification for lateral mass and pars Axis Fracture. Type 1: Pars Fracture $<2 \mathrm{~mm}$ dislocation. Type 2 : Pars Fracture, C2-3 disc disruption, PLL disruption, possible ALL disruption, possible avulsion from C3. Type 2A : More angulation. Type 3 : Facet capsules disruption, dislocation.

A hangman's fracture i.e., a bilateral fracture of the axis pars interarticularis or traumatic spondylolisthesis of the axis was established as the main mechanism of instantaneous death following hanging by Wood-Jones in 1913. However, several earlier reports had already suggested fractures of the cervical spine as the cause of death following hanging. Several classification systems for hangman's fractures co-exist, but the one proposed by Effendi in 1981 has gained the widest acceptance. In Type I, the fracture line goes through the pars interarticularis bilaterally with less than $3 \mathrm{~mm}$ of displacement. A Type II fracture has displacement of more than $3 \mathrm{~mm}$ and Type III an additional C2/3 facet joint displacement.

In 1985, Levine and Edwards modified the Effendi classification (Figure 10). A hangman's fracture is typically a hyperextension injury following traffic accidents and falls. It represents approximately $10-40 \%$ of axis fractures. Effendi type $I$ is the most frequent subtype body fractures are mixed fractures of the second cervical vertebra. They have been referred to by many names and labeled as axis body fractures, nonodontoid fractures, non-hangman's fractures or miscellaneous fractures (including pedicle, superior articulating process, and transverse foramen) of the axis. Their incidence varies depending on the classification. In the series of Greene et al., the incidence of miscellaneous fractures to the axis was $20 \% .^{19,20}$ 


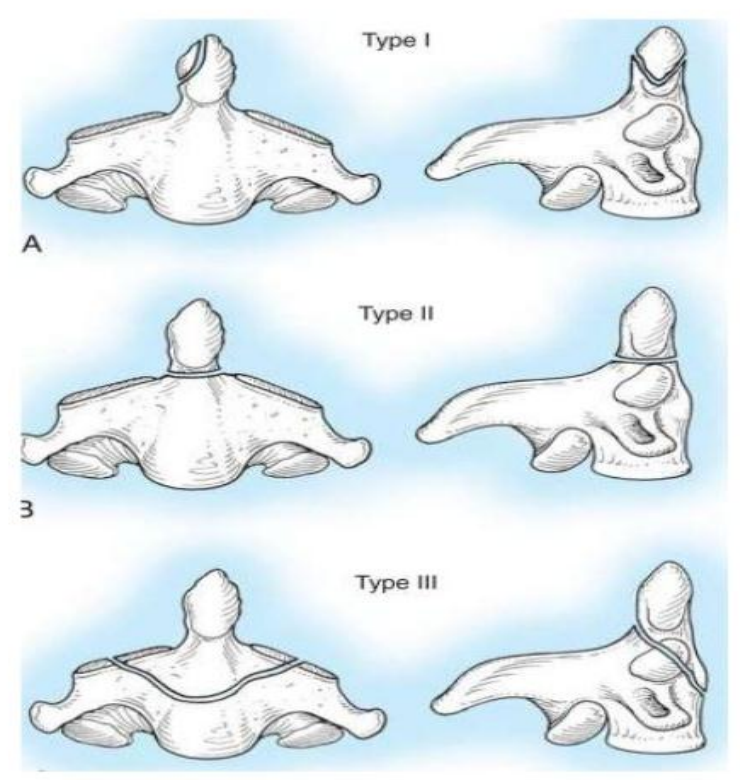

Figure 11. Anderson D'Alanzo Classification for Odontoid Fractures. Type I : avulsion of distal odontoid process. Type II : fracture through the base of the odontoid process. Type III : fracture extending to body of $\mathrm{C} 2$.

\subsection{Epidemiology and incidence of Cervical Trauma}

Cervical trauma occurs in patients in all demographic categories. There are only a few studies on cervical trauma incidence in the general population. A study from Sweden reported the incidence of cervical spine fractures to be $9.2 / 100,000 /$ year in 1999. In the Canadian population between 1981 and $1984 \mathrm{Hu}$ et al. found the incidence of all spine fractures to be $64 / 100,000 / y e a r$. In that study, subgrouping into cervical, thoracic or lumbar fractures was performed for only $45 \%$ of the patients that were admitted to hospitals. The estimated incidence of cervical fractures was 12/100.000/year. A recent study from Norway (2009-2012) reported the incidence of severe CSI to be $16.5 / 100,000$ /year and the incidence of traumatic cervical spine fractures 15.0/100,000/year..$^{21,22,3}$

Cervical trauma incidence in various subpopulations, such as trauma center patients, specific age groups, head injury patients, and patients with a specific injury mechanism has been studied widely, for example, Schoenfeld et al. studied cervical spine fractures in the U.S. military personnel and found an incidence of 29/100,000/year. In blunt trauma populations, the overall incidence of cervical trauma has been reported to range from approximately 2 to $7 \%$. Yanar et al. studied 8,401 pedestrians struck by an automobile in Los Angeles County and found the incidence of cervical trauma to be $2.1 \%$. However, there was a substantial variation with age, ranging from $0.3 \%$ in the pediatric age group to $4.4 \%$ in the age group older than 65 years. The reported incidence of cervical trauma among patients with HI varies approximately from 4$8 \% .^{23}$ 


\subsection{Risk factors for Cervical Trauma}

\subsubsection{Gender, age and injury mechanism}

Male gender is more susceptible for injuries in general and also for cervical trauma. The proportion of male patients is reported around $60-80 \%$ in many cervical trauma studies. The number of patients with a cervical trauma varies with age in bimodal fashion. Young adults and elderly people have the highest cervical trauma incidence. The former is mostly due to road traffic accidents by young males and the latter to ground level falls.

The causes of injury vary between countries, between regions within a country, and between urban and rural locations. Sports injuries, motor vehicle accidents and falls from a height have been described as risk factors for cervical trauma by many authors In recent years, the age distribution has shifted towards elderly people and the mechanism of injury from motor vehicle injuries to ground level falls. ${ }^{2}$

\subsubsection{Alcohol and drugs}

Alcohol is a major risk factor for injuries in general and cervical trauma is not an exception. In Finland, every third fatal injury happens under the influence of alcohol. The rate of alcohol intoxicated patients in trauma centers worldwide ranges from approximately 20 to over $40 \%$. Alcohol use at the time of injury associates especially with cervical spinal cord injury as compared to lower spinal levels.

Non-prescription drugs increase the risk for traumatic injuries, though in Finland, they are not as commonly used as alcohol. However, in recent years their use has increased. For example, a Finnish study showed that between 1977 and 2007, driving under influence of non-prescription drugs increased manifold. In addition to increasing the probability of an accident, alcohol and other drugs can decrease the patient's ability to feel pain. Intoxicated patients with a cervical trauma may report no tenderness in the neck even with a significant injury. ${ }^{24}$

\subsubsection{Head injury}

Sir Geoffrey Jefferson is considered to be the first person to report the coincidence of head trauma and cervical trauma. He observed that any vertical force directed to the vertex of the skull may result in the fracture of the atlas. Since then, several investigators have studied the relationship between HI and cervical trauma with varying results. Foster et al. suggested that "all head and neck trauma patients should be considered to have a cervical spine injury until proven otherwise". 25 


\subsubsection{Ankylosing spinal disorders}

The most common ankylosing spinal disorders are ankylosing spondylitis (AS, also known as Bechterew disease) and diffuse idiopathic skeletal hyperostosis (DISH, also known as Forestier disease). AS is a chronic systemic and inflammatory rheumatic disease with a reported prevalence of up to $1.4 \%$. It mainly affects male.. The prevalence is estimated at between 3 and $25 \%$. The condition is more common in men and the prevalence peaks in the 60 to 69 year old age group. Both of the disorders lead to progressive ossification of the spinal column which makes the spine inflexible and highly susceptible to trauma even after low-energy impacts. The spinal level most often injured in these patients is cervical. ${ }^{26}$

\subsection{Cervical Trauma Diagnostics}

Cervical spine clearance after blunt trauma is defined as accurately confirming the absence of a cervical spine injury. The clearance of the cervical spine in trauma patients are difficult, time consuming, and costly. The objective of cervical spine clearance is to establish that an injury does not exist. Failure to diagnose a cervical trauma at the time of presentation will have disastrous consequences, with a high risk for neurological deterioration. Immobilization in a cervical collar should be initiated at the scene of injury and maintained until a directed examination is performed during the secondary evaluation. However, cervical spine immobilization is not without consequences and should be kept in minimum. ${ }^{27}$

\subsubsection{Clinical evaluation}

Clinical examination is an essential component of the cervical spine clearance process. It includes a review of the history with regard to the injury mechanism and other relevant information (e.g., transient motor or sensory changes may indicate significant spinal pathology, and when noted requires radiographic assessment), identification of pain or tenderness in the head, neck or thoracolumbar spine or any neurologic changes of sensation or muscle strength in the trunk or extremities. ${ }^{28}$

Published Level I evidence shows that asymptomatic, alert, and neurologically intact patients do not need further imaging to declare the cervical spine clear (Hoffman, Mower et al. 2000, Stiell, Wells et al. 2001, Anderson, Muchow et al. 2010). The NEXUS (National Emergency XRadiography Utilization Study Group) method uses specific criteria to identify the low-risk patient who can be cleared clinically without imaging. All of the five following criteria must be met for a patient to be considered low-risk: (i) an awake, alert patient; (ii) no history, signs, or laboratory evidence of intoxication; (iii) no distracting injury; (iv) no cervical spine pain or midline tenderness; and (v) no neurologic signs or symptoms (Hoffman, Mower et al. 2000). The sensitivity of the NEXUS method is excellent $-99.0 \%$ for all cervical injuries and $99.6 \%$ for significant cervical trauma. Due to low specificity (12.9\%),many potentially unnecessary 
radiographs are taken. An alternative to the NEXUS protocol is the Canadian C-Spine Rule. This rule applies to awake, non-intoxicated patients with a GCS score of 15 and identifies those who require radiographs The sensitivity of the Canadian C-Spine rule is reported to be $100 \%$ and the specificity to be $42.5 \%{ }^{29}$

In a separate study, Stiell at al. found that in applying the Canadian C-Spine rule instead of NEXUS criteria, $10 \%$ fewer cases would have required radiographs. In a meta-analysis by Tontz et al. totaling more than 63,000 patients, including three NEXUS, two Canadian Cspine Rule, and nine institutional protocols, the overall sensitivity based on a random effects model was $98.1 \%$, with specificity being $35.0 \%$. Of 28 missed injuries, only 2 were deemed significant but none was associated with neurological deterioration. ${ }^{30}$

\subsubsection{Cervical spine imaging}

Cervical spine imaging is a key element in addition to history and physical examination in trauma patients who are suspected to have a cervical trauma. A patient who has neck pain, midline tenderness, or neurological symptoms requires radiographic imaging. Imaging options are plain radiography, flexion-extension radiography, CT and MRI. If vascular injury is suspected, angiographic studies are needed. Plain radiographs are usually not recommended in the acute phase, because even with the best possible technique, they underestimate the amount of traumatic spine injury and detect only $52-85 \%$ of fractures, even when three views are

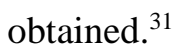

Computed tomography (CT) has supplemented plain radiography in cervical trauma screening and is the primary imaging modality for evaluating patients with a blunt cervical trauma. It detects $97-100 \%$ of fractures to the cervical spine. The imaging must include axial scans from the occiput to the first thoracic vertebra with coronal and sagittal reconstructions. MRI is superior to $\mathrm{CT}$ for the detection of neural, ligamentous, and disc injuries and is primarily employed for the patient who presents with a neurological deficit, or when ligamentous injury is suspected. ${ }^{32}$

Angiographic studies; computed tomography angiography (CTA), magnetic resonance angiography (MRA), and digital subtraction angiography (DSA) are utilized to detect vessel injuries in CSI patients. DSA is the gold standard for detecting VAIs and is the primary imaging modality particularly when endovascular treatment is considered. According to level I evidence, CTA is an alternative to DSA and is usually the primary imaging modality, not least because it is readily available. The advantage of MRA is that it does not use contrast agents and it may be obtained in conjunction with MRI. ${ }^{31}$ 


\subsection{Treatment of Cervical Trauma}

Treatment goal is to provide a stable and painless spine together with the best possible neurological recovery. Principles of definitive treatment for cervical trauma are to realign the spine, to preserve neurological function, to minimize a threat of compression, to stabilize the spine, and to rehabilitate the patient and obtain functional recovery. The chosen treatment strategy of an individual patient is affected by multiple factors. For example, the type of injury, neurological status of the patient, probability of vertebra dislocation, the patient's body habitus and compliance to the treatment should all be taken into account. After the diagnosis of cervical trauma, the short and long-term management should be determined. Long-term management is dependent on the location and pattern of the injury. In the short-term, continued immobilization is usually necessary to prevent further injury (Gardner, Grannum et al. 2005). (49)

Injury to the cervical spine increases mortality and morbidity even without the presence of an SCI. The risk of complications in cervical trauma treatment depends on the injury itself, the preinjury characteristics of the patient and the chosen treatment method. Operative treatment of cervical trauma carries well documented risks, but conservative treatment with cervical collars or halovest devices are not without complications either. Conservative treatment can be initially administered and can serve as an adjunct to surgery, or even be the definitive treatment. Supine skull traction is seldom used, but in some cases, such as facet subluxation or dislocation and burst-type fractures, it may be employed in the initial phase.

Surgical treatment of unstable CSIs usually allows earlier mobilization of the patient and shortens the primary hospital stay. According to the individual patient and injury type, surgery can be performed in numerous ways. Common upper cervical spine procedures include for example anterior odontoid screw fixation, posterior $\mathrm{C} 1-\mathrm{C} 2$ fixation, and occipito-cervical fixation. In the subaxial spine, various methods exist also for anterior and posterior fixation with different kinds of screws, rods, plates and wires. In patients with ankylosing spinal disorders, fractures typically involve the anterior, middle, and posterior columns with high dislocation probability and therefore surgical fixation is often mandatory. In these cases, a posterior or circumferential approach is recommended due to the high failure rate with anterior-only surgeries. ${ }^{26}$ 


\section{REFERENCES}

[1] Krueger, H., Noonan, V.K., Trenaman, L.M., Joshi, P. And Rivers, C.S., 2013. The economic burden of traumatic spinal cord injury in Canada. Chronic diseases and injuries in Canada, 33(3), pp. 113-122.

[2] Hasler, R.M., Exadaktylos, A.K., Bouamra, O., Benneker, L.M., Clancy, M., Sieber, R., Zimmerman, H. and Lecky, F., 2012. Epidemiology and predictors of cervical spine injury in adult major trauma patients: a multicenter cohort study. The journal of trauma and acute caresurgery, 72(4), pp. 975-981

[3] Fredo, H.L., Bakken, I.J., Lied, B., Ronning, P. and Helseth, E., 2014. Incidence of traumatic cervical spine fractures in the Norwegian population: a national registry study. Scandinavian journal of trauma, resuscitation and emergency medicine, 22(1), pp. 78.

[4] Yang, S., Ding, W., Yang, D., Gu, T., Zhang, F., Zhang, D., Sun, Y.,Ma, L. and Song, Y., 2013. Epidemiology and Risk Factors of Cervical Spine Injury during Heating Season in the Patients with Cervical Trauma: A Cross- Sectional Study. PloS one, 8(11), pp. e78358.

[5] Kannus, P., Palvanen, M., Niemi, S. and Parkkari, J., 2007. Alarming rise in the number and incidence of fall-induced cervical spine injuries among older adults. The journals of gerontology. Series A, Biological sciences and medical sciences, 62(2), pp. 180-183.

[6] Vahldiek, J.L., Thieme, S., Hamm, B. and Niehues, S.M., 2017. Incidence of combined cranial and cervical spine injuries in patients with blunt minor trauma: are combined CT examinations of the head and cervical spine justified? Acta Radiologica (Stockholm, Sweden : 1987), 58(7), pp. 856-860.

[7] Williams, P. and Warwick, R., 1980. Gray's anatomy. 36 edn. Great Britain: Churchill Livingstone.

[8] Gardner, A., Grannum, S. and Porter, K., 2005. Cervical spine trauma. Trauma, 7(3), pp. 109-121.

[9] Vaccaro, A.R., Koerner, J.D., Radcliff, K.E., Oner, F.C., Reinhold, M., Schnake, K.J., Kandziora, F., Fehlings, M.G., Dvorak, M.F., Aarabi, B., Rajasekaran, S., Schroeder, G.D., Kepler, C.K. and Vialle, L.R., 2016. AOSpine subaxial cervical spine injury classification system. European spine journal : official publication of the European Spine Society, the European Spinal Deformity Society, and the European Section of the Cervical Spine Research Society, 25(7), pp. 2173-2184.

[10] Debernardi, A., D'Aliberti, G., Talamonti, G., Villa, F., Piparo, M., Ligarotti, G. and Cenzato, M., 2014. Traumatic injuries to the craniovertebral junction: a review of rare events. Neurosurgical review,37(2), pp. 203-216.

[11] Roy, A.K., Miller, B.A., Holland, C.M., Fountain, J.,Arthur J., Pradilla, G. and Ahmad, F.U., 2015. Magnetic resonance imaging of traumatic injury to the craniovertebral junction: a case-based review. Neurosurgical focus, 38(4), pp. E3.

[12] Maserati, M.B., Stephens, B., Zohny, Z., Lee, J.Y., Kanter, A.S., Spiro, R.M. and Okonkwo, D.O., 2009. Occipital condyle fractures: clinical decision rule and surgical management. Journal of neurosurgery. Spine, 11(4), pp. 388-395.

[13] Kakarla, U.K., Chang, S.W., Theodore, N. and Sonntag, V.K., 2010. Atlas fractures. Neurosurgery, 66(3 Suppl), pp. 60-67.

[14] Greene, K.A., Dickman, C.A., Marciano, F.F., Drabier, J.B., Hadley, M.N. and Sonntag, V.K., 1997. Acute axis fractures. Analysis of management and outcome in 340 consecutive cases. Spine, 22(16), pp. 1843- 1852.

[15] Fielding, J.W. and Hawkins, R.J., 1977. Atlanto-axial rotatory fixation. (Fixed rotatory subluxation of the atlanto-axial joint). The Journal of bone and joint surgery. American volume, 59(1), pp. 37-44.

[16] Grauer, J.N., Shafi, B., Hilibrand, A.S., Harrop, J.S., Kwon, B.K., Beiner, J.M., Albert T.J., Fehlings, M.G. and Vaccaro, A.R., 2005. Proposal of a modified, treatmentoriented classification of odontoid fractures. The spine journal : official journal of the North American Spine Society, 5(2), pp. 123-129.

[17] Anderson, L.D. and D'Alonzo, R.T., 1974. Fractures of the odontoid process of the axis. The Journal of bone and joint surgery.American volume, 56(8), pp. 1663-1674. 
[18] Goldberg, W., Mueller, C., Panacek, E., Tigges, S., Hoffman, J.R., Mower, W.R. and Nexus Group, 2001. Distribution and patterns of blunt traumatic cervical spine injury. Annals of Emergency Medicine, 38(1), pp. 17-21.

[19] Effendi, B., Roy, D., Cornish, B., Dussault, R.G. and Laurin, C.A., 1981. Fractures of the ring of the axis. A classification based on the analysis of 131 cases. The Journal of bone and joint surgery. British volume, 63-B(3), pp. 319-327.

[20] Greene, K.A., Dickman, C.A., Marciano, F.F., Drabier, J.B., Hadley, M.N. and Sonntag, V.K., 1997. Acute axis fractures. Analysis of management and outcome in 340 consecutive cases. Spine, 22(16), pp. 1843- 1852.

[21] Brolin, K. and Von Holst, H., 2002. Cervical injuries in Sweden, a national survey of patient data from 1987 to 1999. Injury Control and Safety Promotion, 9(1), pp. 40-52.

[22] Hu, R., Mustard, C.A. and Burns, C., 1996. Epidemiology of incident spinal fracture in a complete population. Spine, 21(4), pp. 492-499.

[23] Yanar, H., Demetriades, D., Hadjizacharia, P., Nomoto, S., Salim, A., Inaba, K., Rhee, P. and Chan, L.S., 2007. Pedestrians injured by automobiles: risk factors for cervical spine injuries. Journal of the American College of Surgeons, 205(6), pp. 794-799.

[24] Ojaniemi, K.K., Lintonen, T.P., Impinen, A.O., Lillsunde, P.M. and Ostamo, A.I., 2009. Trends in driving under the influence of drugs: a register-based study of DUID suspects during 1977-2007. Accident; Analysis and Prevention, 41(1), pp. 191-196.

[25] Foster, C.A., Maisel, R.H. and Meyerhoff, W.L., 1981. Head and neck trauma: initial evaluation, diagnosis and management. Minnesota Medicine, 64(2), pp. 85-90.

[26] Hartmann, S., Tschugg, A., Wipplinger, C. and Thome, C., 2017. Analysis of the Literature on Cervical Spine Fractures in Ankylosing Spinal Disorders. Global spine journal, 7(5), pp. 469-481.

[27] Karason, S., Reynisson, K., Sigvaldason, K. and Sigurdsson, G.H., 2014. Evaluation of clinical efficacy and safety of cervical trauma collars: differences in immobilization, effect on jugular venous pressure and patient comfort. Scandinavian journal of trauma, resuscitation and emergency medicine, 22, pp. 37.

[28] Anderson, P.A., Gugala, Z., Lindsey, R.W., Schoenfeld, A.J. and Harris, M.B., 2010. Clearing the cervical spine in the blunt trauma patient. The Journal of the American Academy of Orthopaedic Surgeons, 18(3), pp. 149-159.

[29] Stiell, I.G., Wells, G.A., Vandemheen, K.L., Clement, C.M., Lesiuk, H., De Maio, V.J., Laupacius, A., Schull, M., McKnight, R.D., Verbeek, R., Brison, R., Cass, D., Dreyer, J., Eisenhauer, M.A., Greenberg, G.H., Macphail, I., Morrison, L., Reardon, $\mathrm{M}$ and Worthington, J., 2001. The Canadian C-Spine Rule for Radiography in Alert and Stable Trauma Patients. JAMA, 286(15), pp. 1841-1848.

[30] Tontz, W., Anderson, P. and Resnick, D., 2006. 3:57119. Clearance of the Asymptomatic Cervical Spine: A Meta-Analysis. The Spine Journal, 6(5), pp. 60.

[31] Hadley, M.N. and Walters, B.C., 2013. Introduction to the Guidelines for the Management of Acute Cervical Spine and Spinal Cord Injuries. Neurosurgery, 72 Suppl 2, pp. 5-16.

[32] Pourtaheri, S., Emami, A., Sinha, K., Faloon, M., Hwang, K., Shafa, E. and Holmes, L.,Jr, 2014. The role of magnetic resonance imaging in acute cervical spine fractures. The spine journal : official journal of the North American Spine Society, 14(11), pp. 2546-2553. 